\title{
Multicenter Cross-Sectional Study on Perceptions and Roles of Community Pharmacists in the Prevention and Management of Cardiovascular Disorders in Northwest Ethiopia
}

\author{
Ashenafi Kibret Sendekie \\ Adeladlew Kassie Netere (iD) \\ Department of Clinical Pharmacy, School \\ of Pharmacy, College of Medicine and \\ Health Sciences, University of Gondar, \\ Gondar, Ethiopia
}

Introduction: Community pharmacy professionals are among the initial healthcare providers and could play crucial roles in preventing and managing cardiovascular disorders. This study aimed to assess perceptions and involvements of community pharmacy professionals in the prevention and management of cardiovascular disorders in Gondar city and nearby rural towns, Northwest Ethiopia.

Methods: A multi-centered cross-sectional survey was conducted on community pharmacy professionals in Gondar city and the nearby rural towns from June to July 2021. Independent sample $t$-test and one-way ANOVA were used to show mean score differences of pharmacists towards the prevention and management of cardiovascular diseases. A 95\% confidence interval with a P-value of $<0.05$ in the tests was considered statistically significant.

Results: Of the 223 initial samples, 210 completed the survey and resulted in a $94.2 \%$ response rate. The average perception and involvement scores of the community pharmacy professionals towards the prevention and treatment of the cardiovascular syndromes were 4.1 and 3.8, respectively. Numerous professionals $(>86 \%)$ agreed on weight reductions, alcohol consumption restrictions and physical exercises to decrease cardiovascular risks. Pharmacy professionals recruited from Gondar city had significantly higher mean scores compared with pharmacy professionals involved from rural towns $(\mathrm{P}<0.001)$. A significant difference in mean involvement score was also noted in regarding the numbers of clients serving/day $(\mathrm{P}=0.026)$.

Conclusion: Community pharmacy professionals had good perceptions on prevention and management of cardiovascular diseases. However, their level of involvement in measuring weight, blood pressure and glucose level, dispensing equipment for home blood pressure and glucose monitoring and keeping records of patients needs to be encouraged. Professionals might benefit from enhanced training to increase their knowledge and confidence.

Keywords: cardiovascular disease, community pharmacists, involvements, perceptions, Ethiopia

\section{Introduction}

Cardiovascular diseases (CVDs) are a group of disorders of heart and blood vessels that includes hypertension (HTN), heart failure (HF), coronary heart disease (CHD), cerebrovascular disease, peripheral arterial disease, rheumatic heart disease (RHD), congenital heart disease (CHD), and venous thromboembolism (VTE). ${ }^{1}$ These disorders are the major cause of global death which have been facing both
Correspondence: Ashenafi Kibret Sendekie

Tel +251918290894

Email ashukib02@yahoo.com;

Ashenafi.kibret@uog.edu.et 
industrialized and non-industrialized countries, and about 17.9 million people are dying every year. For example, in 2019, it accounted for about one-third of all deaths, and these deaths occurred prematurely in people under 70 years. ${ }^{2}$ A systematic review and meta-analysis study conducted in Ethiopia reported that the prevalence of CVDs was ranged from $1-20 \%$ with a pooled prevalence of $5 \%$ and higher in the population who visited hospitals $8 \%{ }^{3}$

The surge in the occurrence of $\mathrm{CV}$ disorders has been linked to various reasons. The disorders are strongly accompanied by the peoples' lifestyle and several physiological aspects that could be ever-changing. Smoking, obesity, physical inactivity, dyslipidemia, unhealthy diet, sedentary lifestyles and diabetes are all associated with several heart diseases and other potential consequences of the $\mathrm{CV}$ disorders such as renal diseases and retinopathy and cerebrovascular diseases. ${ }^{4}$ Additionally, reports in Ethiopia disclosed that alcohol intake, age and abdominal obesities are also additional significant risk factors to the development of the CVDs. ${ }^{5,6}$

Changing the sedentary lifestyle behaviours and optimal control of modifiable risk factors could avoid most CV syndromes. ${ }^{7}$ Further, optimal controls of the modifiable risk factors have been demonstrated to lower the mortality, morbidity and overburdened healthcare systems in both undiagnosed or known CVDs. ${ }^{8}$ Since pharmacists are among the most frequently visited and first points of contact for the general public, they have undeniable importance in preventing CVDs. In addition to dispensing medications, the pharmacist can provide more direct interventions in medication education and disease management as a support to the physician's actions to improve medication adherence, achieve desired therapeutic outcomes, and improve safe medication use practice and humanistic control. ${ }^{9,10}$

By delivering specific chronic illness management services, community pharmacists can make a significant contribution to better patient care. ${ }^{10}$ Community medicine outlets are the initial healthcare sites where patients could have their medications and interventions at community levels. Patients are having difficulty finding primary care physicians, and healthcare prices are fast-growing, thus more community-based care models are being advocated. Community pharmacists can play an important role in improving the health outcomes by means of reducing medication related problems and promoting medication adherences which further limits unnecessary care-provider visits and hospital costs and also advancing an integrated primary care provisions across the healthcare systems. ${ }^{11}$

However, the extent of community pharmacy professionals' (CPPs) involvement in the prevention and treatment of CVDs is not well established in developing countries. To the best of the authors' knowledge and search, it is not investigated in a resource-limited country like Ethiopia, particularly in the study areas. Therefore, this study aimed to assess the perception of CPPs, their extent of involvement towards the prevention and treatment of CVDs in Gondar city and nearby rural towns, Northwest Ethiopia.

\section{Methods and Materials}

\section{Study Design and Settings}

A multi-centered self-reported questionnaire-based crosssectional survey was conducted on the dispensers working in the community drug retail outlets (CMROs) to assess the perception and the level of involvement towards the prevention and treatment of cardiovascular disorders. This self-reported study was conducted in Gondar city and in the nearby rural CMROs, North-western Ethiopia, from June to July 2021. The rural CMROs setting include Teda, Tikil Dingay, Aykel, Ambagiorgies, Dabat, Sanja, Koladiba, Maksegnit, Addis Zemen, Chuahit and Enfranz towns. The Gondar city had about four hundred thousand people as per the World Urbanization Prospects 2021 Population review reports. ${ }^{12}$

\section{Study Populations, Inclusion and Exclusion Criteria}

All volunteer community pharmacy professionals (CPPs) who were working in the CMROs at Gondar city and the nearby rural towns' during the study period were involved in this survey. Those who were not available at the CMROs during the data collection period and refused to participate in the study were excluded.

\section{Sample Size Determination and Sampling Technique}

All the participants included in this study were recruited in Gondar city and its nearby rural towns. Gondar city was purposefully selected; however, the rural towns were selected in lottery methods among the other rural towns. These selected rural settings have been giving comparable pharmaceutical services with Gondar city. All pharmacy professionals in the selected facilities during data 
collection time were approached; however, only volunteer CPPs completed the survey questionnaire.

\section{Operational Definitions}

Community medication retail outlets (CMROs): It is an umbrella term and in the current study it denotes facilities either or all pharmacies and drug stores. ${ }^{13}$

Pharmacy: It represents a drug retail or shop having legal permission to hold and provide any medicine and medical equipment. The personnel who are responsible for licensing should be pharmacists (degree holder). Pharmacy technicians and druggists are supportive in dispensing and not allowed for licensing of pharmacies according to the Ethiopian Food and Drug Authority (EFDA). However, practically druggists and pharmacies might be assigned to involve in medication dispensing in these facilities.

Drug store: Unlike pharmacy, drug store is a drug shop but medicine to be dispensed is limited that means holding every medication in this facility is illegal. For example, holding medication like psychotropic/narcotic is not allowed. Druggists are minimum level of qualification to be licensed for drug store.

Perception: The ability of the respondents to understand or notice in a favorable or unfavorable manner about the risks, preventions and treatment of cardiovascular diseases.

Involvement: Indicates the degree (level) of participation and engagement of the CPPs on promoting, counseling, educating and providing services about the lifestyle modifications, prevention and treatment of cardiovascular disease.

\section{Data Collection Instruments and Procedures}

The tool was first prepared in Amharic (local language), then it was translated to English. It was prepared after reviewing several literatures ${ }^{13-15}$ and important amendments were done considering the local settings. The data collection instrument had 4 parts: (1) the first part contained the socio-demographics; (2) the second part consisted of statements used to assess the level of perceptions of the CPPs in the prevention and mangament of CVDs; (3) the third part was comprehended in the items used to assess the level of involvement of CPPs towards counseling, prevention and treatment of CVDs; and (4) the last part contained items assessing the barriers of CPPs to involve in the prevention and treatment of CVDs
(Additional File). Items used to assess the level of perceptions had 11 statements with five Likert scales (strongly disagree, disagree, neutral, agree, and strongly agree) and scored from 1 to 5 where 1 is strongly disagree and 5 is strongly agree. The levels of perceptions were categorized as poor, moderate and good perceptions after the mean perception score was determined for each participant out of $5(100 \%)$. Respondents scored $<2.5(50 \%) ; 2.5(50 \%)$ to $3.75(75 \%)$ and $>3.75(75 \%)$ had poor, moderate and good level of perceptions, respectively. Similarly, items used to assess the level of involvement had 18 statements with five Likert scales (not at all involved, little involved, uncertain, involved, very involved) with a value of 1 up to 5 points, respectively. It was measured as the overall levels of involvement towards the clients counseling on prevention and treatment of CVDs with a minimum score of 1 to a maximum of 5 points. Reliability test was done for both items used to assess perception and involvements of the respondants, and resulted the Cronbach's alpha $(\alpha)$ values of 0.86 and 0.88 for the perception and involvement items, respectively.

\section{Data Quality Management, Entry and Statistical Analysis}

The data was entered into SPSS version 26 and was analyzed after it was checked for cleanness, completeness and consistency. Data were collected by two clinical pharmacists after trained for a half-day data on the aspect of data collection tool and ethical issues. During data collection, the study participants were clear about the objective of the study. Histogram and Q-Q plot were used to test the normality of continuous variables. The results were described by means and standard divisions $( \pm \mathrm{SD})$ for continuous variables, and frequencies and percentages for categorical variables. An independent $t$-test and a one-way ANOVA were employed to explore the mean score difference in regard to involvement in the prevention and management of CVDs among respondents. A 95\% confidence interval (CI) with a P-value of $<0.05$ in the tests was considered statistically significant.

\section{Ethical Considerations}

The proposal had legitimate approval by the institutional review board (IRB) of the University of Gondar, research and ethics committee of the school of pharmacy with a reference number UOG-Sop/262/2021. The ethical 
clearance was obtained from the school of pharmacy at the University of Gondar before conducting the study. Participants were informed both in written and verbally by explaining the aim and objective of the study to the study participants beforehand and informed them that if they do not want to take part in the study. The data collection procedure was conducted as per the COVID19 protocol. Confidentiality was ensured by making all the provided information was anonymous.

\section{Results}

\section{Socio-Demographic Characteristics of the Study Participants}

From a total of 223 CPPs approached, 210 completed the self-administered survey resulting in a $94.2 \%$ response rate. The majority of the participants $(69.5 \%)$ were from Gondar city, while the rest were from the adjacent rural towns. More than half (52.4\%) were males with a mean $( \pm \mathrm{SD})$ age of $31.8( \pm 8.2)$. A higher proportion of the respondents $(48.1 \%)$ had work experience of $1-5$ years, and $45.7 \%$ of them were pharmacy technicians. Despite most (86.2\%) of the community pharmacy professionals knowing whether there is always better about CVDs prevention and management, only few $(33.8 \%)$ were trained for the prevention and treatment strategies of CVDs (Table 1).

\section{Level of Perceptions on Prevention and Treatment of the Cardiovascular Diseases}

The overall mean perception score of the CPPs on the CVDs risk, prevention and treatment was $4.10( \pm 0.80)$ out of 5-point Likert scales. Regarding the perceptions, the majority of the community pharmacy professionals had agreed and strongly agreed towards the risks, prevention and treatment of CVDs. As a result, significant numbers of the respondents (81\%) had scored $4.29( \pm$ 0.3 ) and were categorized as having a good perception towards the risks, preventions and treatment of CVDs. Whereas, the rest $(19 \%)$ scored $3.29 \quad( \pm 0.4)$ had a moderate level of perception. Most of the respondents (80.5\%) agreed that cardiovascular diseases are common and have been increasing in Ethiopia and most of them (85.7\%) perceived that CVDs relates largely to obesity and sedentary lifestyle. Approximately eighty-five percent of the CPPs believed that more attention should be given to lifestyle modifications. Numerous CPPs (>86\%) agreed
Table I Socio-Demographic Characteristics of the Community Pharmacy Professionals, Northwest Ethiopia, 202I ( $N=210)$

\begin{tabular}{|c|c|c|c|}
\hline Variables & Category & Frequency & Percent \\
\hline Sex & $\begin{array}{l}\text { Male } \\
\text { Female }\end{array}$ & $\begin{array}{l}110 \\
100\end{array}$ & $\begin{array}{l}52.4 \\
47.6\end{array}$ \\
\hline $\begin{array}{l}\text { Age in (year): Mean } \\
( \pm S D)\end{array}$ & $31.6 \pm(8.2)$ & & \\
\hline $\begin{array}{l}\text { Settings participants } \\
\text { involved }\end{array}$ & $\begin{array}{l}\text { Gondar city } \\
\text { Rural towns }\end{array}$ & $\begin{array}{l}146 \\
64\end{array}$ & $\begin{array}{l}69.5 \\
30.5\end{array}$ \\
\hline Work experience & $\begin{array}{l}<1 \text { year } \\
1-5 \text { Years } \\
>5 \text { years }\end{array}$ & $\begin{array}{l}39 \\
101 \\
70\end{array}$ & $\begin{array}{l}18.6 \\
48.1 \\
33.3\end{array}$ \\
\hline Qualification status & $\begin{array}{l}\text { Pharmacy technician } \\
\text { Druggist } \\
\text { Degree holder }\end{array}$ & $\begin{array}{l}96 \\
73 \\
41\end{array}$ & $\begin{array}{l}45.7 \\
34.8 \\
19.5\end{array}$ \\
\hline $\begin{array}{l}\text { Monthly income } \\
\text { (Birr) }\end{array}$ & $\begin{array}{l}1500-2999 \\
3000-4999 \\
\geq 5000\end{array}$ & $\begin{array}{l}63 \\
93 \\
54\end{array}$ & $\begin{array}{l}30 \\
44.3 \\
25.7\end{array}$ \\
\hline $\begin{array}{l}\text { Type of CMROs } \\
\text { respondents involved } \\
\text { from }\end{array}$ & $\begin{array}{l}\text { Drug store } \\
\text { Pharmacy }\end{array}$ & $\begin{array}{l}91 \\
119\end{array}$ & $\begin{array}{l}43.3 \\
56.7\end{array}$ \\
\hline $\begin{array}{l}\text { Numbers of clients } \\
\text { served per day }\end{array}$ & $\begin{array}{l}<50 \\
50-100 \\
>100\end{array}$ & $\begin{array}{l}115 \\
82 \\
13\end{array}$ & $\begin{array}{l}54.8 \\
39 \\
6.2\end{array}$ \\
\hline Working hours/day & $\begin{array}{l}\leq 8 \text { hours } \\
>8 \text { hours }\end{array}$ & $\begin{array}{l}91 \\
119\end{array}$ & $\begin{array}{l}43.3 \\
56.7\end{array}$ \\
\hline $\begin{array}{l}\text { Previously trained on } \\
\text { the CVDs prevention } \\
\text { and management } \\
\text { methods }\end{array}$ & $\begin{array}{l}\text { Yes } \\
\text { No }\end{array}$ & $\begin{array}{l}71 \\
139\end{array}$ & $\begin{array}{l}33.8 \\
66.2\end{array}$ \\
\hline $\begin{array}{l}\text { Knowing whether } \\
\text { there is always better } \\
\text { prevention and } \\
\text { management of } \\
\text { CVDs }\end{array}$ & $\begin{array}{l}\text { Yes } \\
\text { No }\end{array}$ & $\begin{array}{l}181 \\
29\end{array}$ & $\begin{array}{l}86.2 \\
13.8\end{array}$ \\
\hline
\end{tabular}

that following healthy weight reductions, alcohol consumption restrictions and physical exercises could decrease cardiovascular risks. Most of the CPPs perceived that alcohol consumptions restrictions (89.5\%) and documenting drug refill history $(79.5 \%)$ were used to prevent the $\mathrm{CV}$ risks and important to evaluate it. Generally, the mean perception score that the CPPs had on promoting physical activities, alcohol consumptions, smoking cessation, and salt restrictions was $>4$, while it was less than 4 for the remaining statements out of the 5 Likert scales (Table 2). 
Table 2 Percentage Distribution of Community Pharmacy Professionals' Perception on the Risks, Preventions and Treatment of Cardiovascular Disease

\begin{tabular}{|c|c|c|c|c|c|c|}
\hline $\begin{array}{l}\text { Items to Assess Perceptions on the Risks, } \\
\text { Preventions and Treatment of CVDs }\end{array}$ & $\begin{array}{l}\text { Strongly } \\
\text { Disagree (\%) }\end{array}$ & Disagree (\%) & Neutral (\%) & Agree (\%) & $\begin{array}{l}\text { Strongly } \\
\text { Agree (\%) }\end{array}$ & $\begin{array}{l}\text { Mean } \\
( \pm S D)\end{array}$ \\
\hline CVDs are common and is increasing in Ethiopia & $\mathrm{I}(0.5)$ & $7(3.3)$ & $33(15.7)$ & $107(5 \mathrm{I})$ & $62(29.5)$ & $4.06( \pm 0.79)$ \\
\hline $\begin{array}{l}\text { CVDs relates largely to obesity and sedentary } \\
\text { lifestyles }\end{array}$ & 0 & $9(4.3)$ & $21(10)$ & $124(59)$ & $56(26.7)$ & $4.08( \pm 0.73)$ \\
\hline $\begin{array}{l}\text { More attentions must be given for lifestyles } \\
\text { modification to general population }\end{array}$ & $2(1)$ & $12(5.7)$ & $18(8.6)$ & $115(54.8)$ & $63(30)$ & $4.07( \pm 0.84)$ \\
\hline $\begin{array}{l}\text { Patients with CVDs need to be early identified so } \\
\text { that risk factors could be reduce }\end{array}$ & 0 & $9(4.3)$ & $22(10.5)$ & $123(58.6)$ & $56(26.7)$ & $4.08( \pm 0.74)$ \\
\hline Weight loss program decrease $\mathrm{CV}$ risks & $2(1)$ & II (5.2) & 14 6.7) & $116(55.2)$ & $67(31.4)$ & $4.12( \pm 0.82)$ \\
\hline Physical exercises could decrease CV risks & $3(1.4)$ & $7(3.3)$ & $15(7.1)$ & III (52.9) & $74(37.2)$ & $4.17( \pm 0.81)$ \\
\hline $\begin{array}{l}\text { Prescribed medications could be important for } \\
\text { the treatment of CVDs }\end{array}$ & 0 & $8(3.8)$ & $14(6.7)$ & $114(54.3)$ & $74(35.2)$ & $4.21( \pm 0.73)$ \\
\hline $\begin{array}{l}\text { Dietary modifications and herbals are used to } \\
\text { decrease CV risks }\end{array}$ & $4(1.9)$ & $18(8.6)$ & $3 I(14.8)$ & $123(58.6)$ & $34(16.2)$ & $3.79( \pm 0.88)$ \\
\hline Alcohol restriction is used to prevent $\mathrm{CVs}$ risks & $2(1)$ & II (5.2) & $9(4.3)$ & $108(5 \mid .4)$ & $80(38.1)$ & $4.20( \pm 0.83)$ \\
\hline $\begin{array}{l}\text { Early screening of patients is important to prevent } \\
\text { severe outcomes }\end{array}$ & $\mathrm{I}(0.5)$ & $10(4.8)$ & $20(9.5)$ & $82(39)$ & $97(46.2)$ & $4.26( \pm 0.85)$ \\
\hline $\begin{array}{l}\text { Documenting drug refill history is important for } \\
\text { CVDs evaluation }\end{array}$ & $\mathrm{I}(0.5)$ & $10(4.8)$ & $32(15.2)$ & $105(50)$ & $62(29.5)$ & $4.03( \pm 0.83)$ \\
\hline
\end{tabular}

\section{Involvement of Participants Towards Prevention and Treatment of Cardiovascular Diseases}

The overall average involvement score of the community pharmacy professionals towards the prevention and treatment of the CVDs was 3.77 ( \pm 0.60$)$ out of 5-point Likert scales. Most of the CPPs responded from involved to very involved in most of the items indicating the involvements of prevention and treatment of the cardiovascular diseases. More than three-fourths $(76.7 \%)$ of pharmacy professionals were involved in advising patients on healthy weight reductions by consuming low-calorie diets. In addition, most CPPs ( $>81 \%)$ were comprehensively involved in advising patients on promoting physical activities, counseling on alcohol consumption, smoking secessions and salt restrictions. On the other hand, the percentage of pharmacists who involved in screening and blood pressure (BP) measurements, weight and glucose level, monitoring the patients' response to the treatment, keeping records of patients care services in the pharmacy and selling equipment for home measurement of BP and blood glucose was low $(<65 \%)$.
Generally, the mean involvement scores that the CPPs were advising on promoting physical activities, alcohol consumptions, smoking cessation, and salt restrictions were $>4$, while it was less than 4 for the remaining statements out of the 5 Likert scales (Figure 1 and Table 3).

\section{The Participants' Involvement Difference Towards Prevention and Treatment of CVDs}

An independent $t$-test was employed to appreciate the mean score difference among variables regarding the overall involvement in the prevention and management of CVDs. Pharmacy professionals recruited from Gondar city $(\mathrm{mean}=3.90)$ had significantly $(\mathrm{t}=5.21, \mathrm{P}=0.000)$ higher mean scores compared with CPPs involved from rural towns (mean=3.47). However, there was no significant difference in the average scores between sex category ( $\mathrm{P}=0.621)$, CMRO types $(\mathrm{P}=0.480)$, working hours $(\mathrm{P}=0.083)$, and status of training $(\mathrm{P}=0.367)$ (Table 4).

A one-way ANOVA test showed that there was a significant difference in the mean involvement score of 


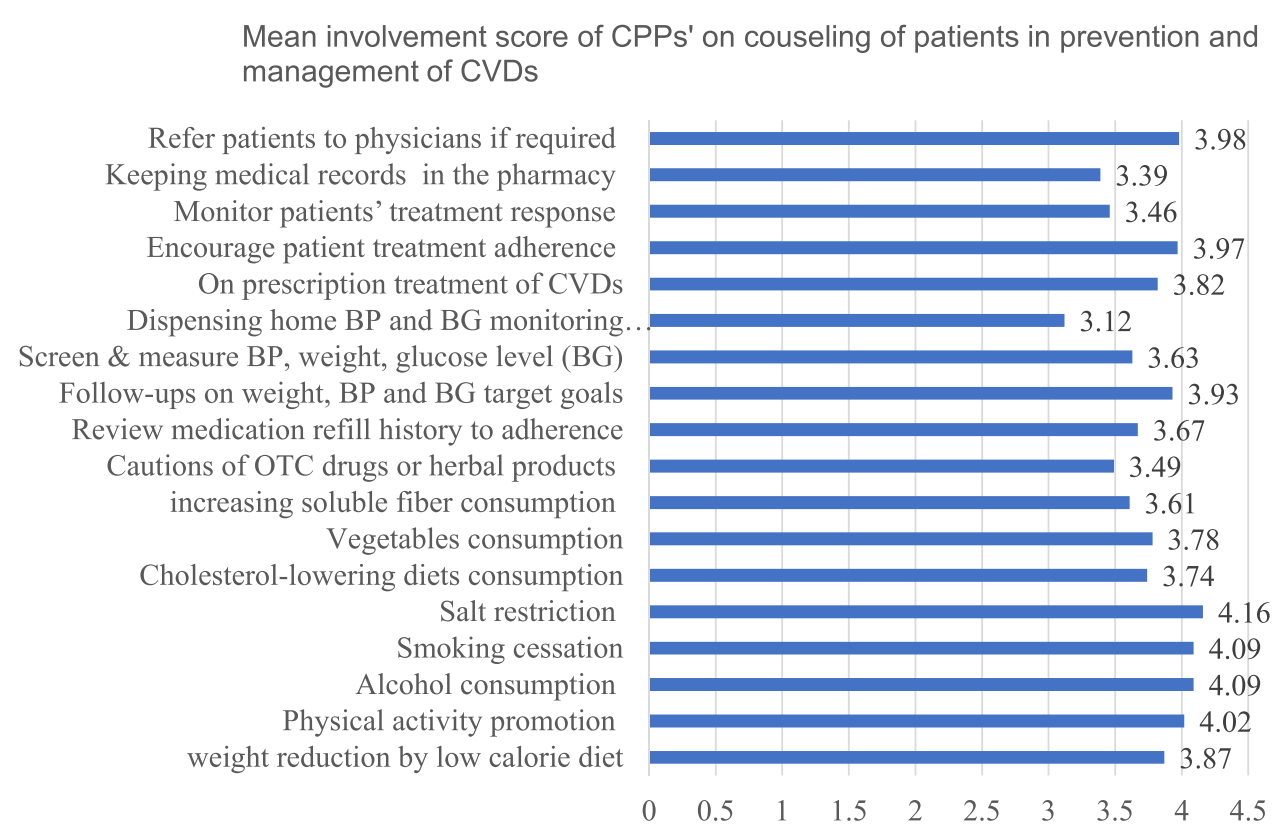

Figure I Mean involvement score of pharmacy professionals on counseling in the prevention and management of cardiovascular diseases in Northwestern Ethiopia from June to July 2021.

CPPs' regarding the numbers of clients serving/day $(\mathrm{F}=3.72, \mathrm{P}=0.026)$. The Tukey Post Hoc test disclosed that CPPs who had been served $<50$ clients/day had higher involvement scores $($ mean $=3.77)$ compared with those who served $>100$ clients/day (mean=3.36) $(p=0.047)$ and CPPs who served 50-100 clients/day also had higher involvement scores (mean=3.83) compared with those who served $>100$ clients/day $($ mean $=3.36)$ $(\mathrm{P}=0.019)$. However, the involvement mean scores among participants with difference in work experiences $(\mathrm{P}=0.380)$, qualification levels $(\mathrm{P}=0.549)$ and monthly incomes $(\mathrm{P}=0.265)$ was insignificant (Table 5).

\section{Barriers to Involve on Prevention and Treatment of Cardiovascular Diseases}

Based on the respondents' self-reports, lack of clients private counseling area in CMROs (48.1\%) followed by the lack of time or increase in workload (34.3\%) and lack of educational materials $(27.1 \%)$ were the most common barriers to be involved in preventing and managing the cardiovascular diseases (Figure 2).

\section{Discussion}

Community pharmacy professionals have varying public health impacts from their primary dispensing roles to a more comprehensive involvement on the healthcare issues and recognized in the whole world. ${ }^{11,16}$ This multicenter survey had explored the levels of perception and extent of involvement of CPPs in the preventions and managements of the cardiovascular diseases in Gondar city and surrounding rural towns. In the present study, the CPPs had scored good levels of perception and involvement ranges towards the prevention and treatment approaches on the CV syndromes. The results highlighted that the CPPs were almost "agreed to strongly agreed" with the most important points of perceptions to reduce the risks, promoting prevention methods and line up to the treatment approaches of the CV disorders. Numerous participants had good levels of perception about the risks, preventions and management of CVDs, and this is in good agreement with the study reported from Malaysia. ${ }^{14}$

Another most marked observation to emerge from the study revealed that majority of the CPPs agreed that CVDs are common and have been increasing in Ethiopia, and around $86 \%$ of the surveyed perceived that this was largely related to obesity and sedentary lifestyles. This was in complete agreement with the reports in Kuwait ${ }^{17}$ and USA where several CPPs agreed that chronic heart diseases are current public challenges. ${ }^{18}$ Hence, significant respondents believed that more attention should be given to lifestyle modifications. Further, numerous pharmacists (>86\%) also agreed that following healthy weight reductions, alcohol consumption restrictions and physical exercises could decrease the potential risks of cardiovascular syndromes. These study findings have a number of 
Table 3 Percentage Distribution of Community Pharmacy Professionals' Involvement Towards the Preventions and Treatments of CVDs

\begin{tabular}{|c|c|c|c|c|c|}
\hline $\begin{array}{l}\text { Item Focused on Advising and Counseling Involvement of } \\
\text { CPPs }\end{array}$ & $\begin{array}{l}\text { Not } \\
\text { Involved }\end{array}$ & $\begin{array}{l}\text { Little } \\
\text { Involved }\end{array}$ & Uncertain & Involved & $\begin{array}{l}\text { Very } \\
\text { Involved }\end{array}$ \\
\hline Weight reduction by low calorie diet & $3(1.4 \%)$ & $28(13.3 \%)$ & $18(8.6 \%)$ & $105(50 \%)$ & $56(26.7 \%)$ \\
\hline Physical activity promotion & $3(1.4 \%)$ & $22(10.5 \%)$ & $12(5.7 \%)$ & $103(49.1 \%)$ & $70(33.3 \%)$ \\
\hline Alcohol consumption & $4(1.9 \%)$ & $19(9.1 \%)$ & $15(7.1 \%)$ & 89 (42.4\%) & $83(39.5 \%)$ \\
\hline Smoking cessation & $6(2.9 \%)$ & $16(7.6 \%)$ & $15(7.1 \%)$ & $90(42.9 \%)$ & $83(39.5 \%)$ \\
\hline Salt restriction & $3(1.4 \%)$ & $16(7.6 \%)$ & $14(6.7 \%)$ & $88(41.9 \%)$ & $89(42.4 \%)$ \\
\hline Cholesterol-lowering diets consumption & $3(1.4 \%)$ & 27 (I2.9\%) & $26(12.4 \%)$ & $119(56.7 \%)$ & $35(16.7 \%)$ \\
\hline Vegetables consumption & $3(1.4 \%)$ & $32(15.2 \%)$ & $23(11 \%)$ & $102(48.6 \%)$ & $50(23.8 \%)$ \\
\hline Increasing soluble fiber consumption & $4(1.9 \%)$ & $33(15.7 \%)$ & $35(16.7 \%)$ & $107(5 \mid \%)$ & $31(14.8 \%)$ \\
\hline Cautions of OTC drugs or herbal products & $6(2.9 \%)$ & $50(23.8 \%)$ & $24(11.4 \%)$ & $95(45.2 \%)$ & $35(16.7 \%)$ \\
\hline Review medication refill history to adherence & $4(1.9 \%)$ & $34(16.2 \%)$ & $30(\mid 4.3 \%)$ & $102(48.6 \%)$ & $40(19.0 \%)$ \\
\hline Follow-ups on weight, BP and BG target goals & $2(1 \%)$ & $31(14.8 \%)$ & $12(5.7 \%)$ & 99 (47.1\%) & $66(31.4 \%)$ \\
\hline Screen \& measure BP, weight and glucose level (BG) & $7(3.3 \%)$ & $46(21.9 \%)$ & $20(9.5 \%)$ & $81(38.6 \%)$ & $56(26.7 \%)$ \\
\hline Dispensing home BP and BG monitoring apparatus & $23(11 \%)$ & $6 \mathrm{I}(29.0 \%)$ & $31(14.8 \%)$ & $57(27.1 \%)$ & $38(18.1 \%)$ \\
\hline On prescription treatment of CVDs & $I(0.5)$ & $32(15.2 \%)$ & $20(9.5 \%)$ & $109(51.9 \%)$ & $48(22.9 \%)$ \\
\hline Encourage patient treatment adherence & I (0.5) & $22(10.5 \%)$ & $19(9 \%)$ & $109(51.9 \%)$ & $59(28.1 \%)$ \\
\hline Monitor patients' treatment response & $4(1.9 \%)$ & $50(23.8 \%)$ & $33(15.7 \%)$ & $92(43.8 \%)$ & $31(14.8 \%)$ \\
\hline Keeping medical records in the pharmacy & $\mathrm{II}(5.2 \%)$ & $50(23.3 \%)$ & $29(13.8 \%)$ & $86(41 \%)$ & $34(16.2 \%)$ \\
\hline Refer patients to physicians if required & $3(1.4 \%)$ & 27 (I2.9\%) & $16(7.6 \%)$ & 89 (42.4\%) & $75(35.7 \%)$ \\
\hline
\end{tabular}

Abbreviations: OTC, over the counter; BP, blood pressure; BG, blood glucose.

similarities with previous studies done in Gondar city. ${ }^{13,19}$ It is very likely that participants may have enormously increased their awareness and attitudes towards the common health care priorities and risks of CVDs. This substantiates to the previous national study in Lebanon that stated as CPPs agreed on the role of weight reduction. ${ }^{20}$

Most CPPs had various degree of involvements (involved to very involved) in most of basic encouragement points on prevention and stimulating on $\mathrm{CV}$ disease treatment. It could thus reasonably be assumed that the pharmacy professionals have been involved in patient educations and counseling approaches following the new development of the country's curricular systems having a paradigm shift from dispensing practices to clients'oriented approaches. Thereby, several CPPs reported they had knowledge about CVDs prevention and management. With this, several pharmacy professionals working as dispensers in medication outlets have been graduated after equipped with various clinical scenarios and case approaches along with clients' approaches and communication skills on $\mathrm{CV}$ disorders management. Contrastingly, fewer CPPs were trained regarding the prevention and treatment strategies of $\mathrm{CV}$ disorders. This could be possibly justified as community health authorities and officials have not been involved in taking initiatives and endorsements on trainings as well as regular up-to-dating dispensers. Moreover, the inter-collaborations among the CMROs, health authorities and concerned educational training centers could be attributed to insufficient.

Significant numbers of CPPs had been involved on advising patients to practice healthy weight reductions using lowcalorie diets, controlling alcohol consumptions, promoting physical exercises, smoking secessions and salt restrictions. In our view, the result highlighted that majority of the surveyed 
Table 4 Independent $t$-Test of Differences Among Categories of the Respondents in Overall Involvement Towards Prevention and Management of Cardiovascular Diseases

\begin{tabular}{|c|c|c|c|c|}
\hline \multirow[t]{2}{*}{ Variables } & \multirow[t]{2}{*}{ Category } & \multicolumn{3}{|c|}{$\begin{array}{l}\text { Overall Involvement Towards Prevention and } \\
\text { Management of CVDs }\end{array}$} \\
\hline & & Mean (士SD) & $\mathbf{t}$ & P-value \\
\hline Sex & $\begin{array}{l}\text { Male } \\
\text { Female }\end{array}$ & $\begin{array}{l}3.79(0.58) \\
3.75(0.60)\end{array}$ & 0.50 & 0.621 \\
\hline Setting participants involved & $\begin{array}{l}\text { Gondar city } \\
\text { Rural towns }\end{array}$ & $\begin{array}{l}3.90(0.55) \\
3.47(0.56)\end{array}$ & 5.21 & $0.000 *$ \\
\hline Type of CMROs respondents involved & $\begin{array}{l}\text { Drug store } \\
\text { Pharmacy }\end{array}$ & $\begin{array}{l}3.74(0.58) \\
3.79(0.59)\end{array}$ & -0.71 & 0.480 \\
\hline Working hour per day & $\begin{array}{l}\leq 8 \text { hours } \\
>8 \text { hours }\end{array}$ & $\begin{array}{l}3.69(0.62) \\
3.83(0.55)\end{array}$ & -1.75 & 0.083 \\
\hline Previous training on CVDs & $\begin{array}{l}\text { Yes } \\
\text { No }\end{array}$ & $\begin{array}{l}3.82(0.59) \\
3.74(0.58)\end{array}$ & 0.91 & 0.367 \\
\hline Do you know about the risks, the prevention and management of CVDs & $\begin{array}{l}\text { Yes } \\
\text { No }\end{array}$ & $\begin{array}{l}3.76(0.58) \\
3.82(0.65)\end{array}$ & -0.44 & 0.663 \\
\hline
\end{tabular}

Note: * Denotes significantly associated at $\mathrm{p}$-value $<0.05$.

Table 5 Statistical Test (One-Way ANOVA) of Differences Among Categories of the Respondents in Overall Involvement Towards Prevention and Management of Cardiovascular Diseases

\begin{tabular}{|c|c|c|c|c|}
\hline \multirow[t]{2}{*}{ Variables } & \multirow[t]{2}{*}{ Category } & \multicolumn{3}{|c|}{ Overall Involvement Towards Prevention and Management of CVDs } \\
\hline & & Mean (士SD) & $\mathbf{F}$ & P-value \\
\hline Work experience: Years & $\begin{array}{l}<1 \\
1-5 \\
>5\end{array}$ & $\begin{array}{l}3.69(0.69) \\
3.82(0.53) \\
3.73(0.59)\end{array}$ & 0.97 & 0.380 \\
\hline Qualification level & $\begin{array}{l}\text { Pharmacy technician } \\
\text { Druggist } \\
\text { Graduate degree and above }\end{array}$ & $\begin{array}{l}3.75(0.62) \\
3.83(0.56) \\
3.7 I(0.55)\end{array}$ & 0.60 & 0.549 \\
\hline Monthly income (birr) & $\begin{array}{l}1500-2999 \\
3000-4999 \\
\geq 5000\end{array}$ & $\begin{array}{l}3.7 I(0.65) \\
3.74(0.59) \\
3.88(0.48)\end{array}$ & 1.34 & 0.265 \\
\hline Clients served/day & $\begin{array}{l}<50 \\
50-100 \\
>100\end{array}$ & $\begin{array}{l}3.77(0.58) \\
3.83(0.58) \\
3.36(0.49)\end{array}$ & 3.72 & $0.026^{*}$ \\
\hline
\end{tabular}

Note: $*$ Indicates significantly associated at $\mathrm{p}$-value $<0.05$.

have good involvement on $\mathrm{CV}$ disorders management practices. These results are in line to several studies done in many countries, ${ }^{21-23}$ in which most of CPPs were involved in activities typically related to promote lifestyle modifications and CVDs preventions. In contrast, involvement towards advising on alcohol consumptions and smoking cessations were higher compared with other studies. ${ }^{14,24}$ These results might suggest that an increase in sedentary lifestyles of the community became the concern of the professionals and initiates them to be involved on counseling on the risks of alcohol consumption and smoking habits which leads to higher involvements of CPPs.

On the other hand, just under two-thirds of CPPs have been involved in screening and measuring BP, glucose and weight levels, monitoring patients' response to treatments, keeping medical records in the pharmacy and dispensing 


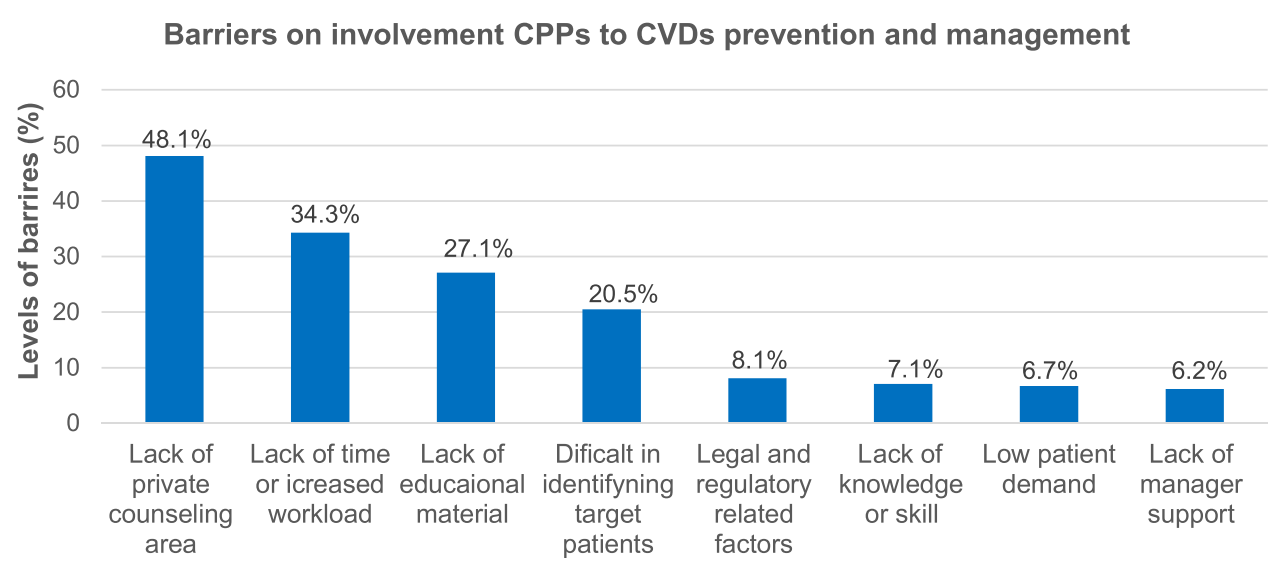

Figure 2 Barriers of community pharmacy professionals to involve in the prevention and management of cardiovascular diseases in Northwestern Ethiopia from June to July 202I.

home BP and glucose measuring apparatuses. Lower involvement levels would seem to be implied that CPPs were not inclusively counseling all basic points concerning to $\mathrm{CV}$ disorders. These lower involvement levels are correlated to an Ethiopian previous report. ${ }^{13}$ However, it was far lower than the study conducted in Malaysia ${ }^{14}$ and Kuwait. ${ }^{17}$ Further, the percentage of CPPs involved in monitoring patients' response to the treatment was lower compared with a study done earlier in Kuwait. ${ }^{17}$ The foremost discrepancy might be due to professionals were poorly involved on some selected intervention points and could have gaps on skills or commitments. The gaps could suggest more attention is required towards improving counselling and involvements in pharmaceutical cares.

The current study highlighted that higher mean involvement scores were noticed in participants recruited from Gondar city compared with the rural settings. The possible reason for these differences might be CPPs in Gondar city could easily access the timely updated resources regarding CV disorders. Moreover, CPPs in Gondar might have faced patients with various clinical conditions who need updated CVDs prevention and management methods; in return, it leads to be highly involved on advising prevention and management strategies. The CPPs served lower numbers of clients/ day had higher average involvement scores than those who served more client numbers. This might be partially justified that those who served more clients may be tired and being too busy to adequately engage in counseling services, rather they may practice traditional medicine dispensing methods to avoid patient load. The results suggest that CPPs should serve an optimum number of clients to provide effective services so that they could deliver better counseling and pharmaceutical services to the patients.
In this study, lack of private counseling areas and supportive materials, increased workload and insufficient time were the top perceived barriers of CPPs to be involved in prevention and treatment of CVDs. Our findings shared a number of similarities with the studies from Malaysia ${ }^{14}$ and Qatar. $^{25}$ Taken together, these results suggested the commonest barriers and are similar to different study settings; therefore, problem-based attention could be required to reduce the effects of barriers which potentially hindered the professionals' involvement towards prevention and management of CVDs.

Generally, this research has highlighted the roles of CPPs in prevention and management of CVDs that could be extended beyond the traditional practices of medication dispensation. These roles range from screening and monitoring of clinical conditions like BP, weight and glucose levels to interventions on lifestyle modifications such as alcohol consumption, smoking cessation, salt restriction and medicines management and adherence. This was correlated and supported by different studies. ${ }^{26-29}$ Promoting healthy behaviours of the general public is a key population strategy for reducing its burden and this may also be the driving point to CPPs for actively engaging to deliver cardiovascular disease prevention and treatment.

This study has some limitations. First, the results of the study may not be generalized for all CPPs in the country; because of small sample size was used. The data collection which depends on honesty and faith to the respondents could affect the responses resulting in an overestimation of current practice and perception. Despite the above limitations, the current study was aimed to assess CPPs' perceptions about CVDs, describe their perception level about prevention and treatments of CVDs and explore their 
extent of involvement in Gondar city and nearby rural towns. We hope that this study will fill to the existing literatures gap in the area of CPPs' roles to handle the $\mathrm{CV}$ conditions, and also believed to inform policy makers to integrate the CMROs in nationwide efforts of CVDs management approaches and improve practices.

\section{Conclusion}

Community pharmacy professionals provided counseling to prevent and manage patients with cardiovascular diseases to some extent and most of them had good perception in the prevention and management strategies. However, their level of involvement in measuring weight, BP and glucose level, dispensing equipment for home blood pressure and glucose monitoring and keeping records of patients need to be encouraged in order to enhance patient care service. Providing continuous trainings and guidelines which will help CPPs practices for CVDs screening, lifestyle modification, and prevention and treatment strategies particularly for rural setting pharmacy professionals could be encouraged to increase their confidence and involvement in patient care of CVDs.

\section{Abbreviations}

CPPs, Community Pharmacy Professionals; CMROs, Community Drug Retail Outlets; CVDs, Cardiovascular Diseases.

\section{Data Sharing Statement}

All necessary data are available from the manuscript. We will share the available dataset if required.

\section{Acknowledgment}

The authors would like to thank the data collectors and participants.

\section{Author Contributions}

All authors made a significant contribution to the work reported, whether that is in the conception, study design, execution, acquisition of data, analysis and interpretation, or in all these areas; took part in drafting, revising or critically reviewing the article; gave final approval of the version to be published; have agreed on the journal to which the article has been submitted; and agree to be accountable for all aspects of the work.

\section{Funding}

There is no funding to report.

\section{Disclosure}

The authors state that they have no conflicts of interest.

\section{References}

1. Tijburg L, Mattern T, Folts J, Weisgerber U, Katan M. Tea flavonoids and cardiovascular diseases: a review. Crit Rev Food Sci Nutr. 1997;37(8):771-785. doi:10.1080/10408399709527802

2. Roth GA, Mensah GA, Johnson CO, et al. Global burden of cardiovascular diseases and risk factors, 1990-2019: update from the GBD 2019 study. J Am Coll Cardiol. 2020;76(25):2982-3021. doi:10.1016/ j.jacc.2020.11.010

3. Angaw DA, Ali R, Tadele A, Shumet S. The prevalence of cardiovascular disease in Ethiopia: a systematic review and meta-analysis of institutional and community-based studies. BMC Cardiovasc Disord. 2021;21(1):37. doi:10.1186/s12872-020-01828-z

4. Awad A, Al-Nafisi H. Public knowledge of cardiovascular disease and its risk factors in Kuwait: a cross-sectional survey. BMC Public Health. 2014;14(1):1-11. doi:10.1186/1471-2458-14-1131

5. Ali S, Misganaw A, Worku A, et al. The burden of cardiovascular diseases in Ethiopia from 1990 to 2017: evidence from the global burden of disease study. Int Health. 2021;13(4):318-326. doi:10. 1093/inthealth/ihaa069

6. Aragaw S, Tesfahun E, Derseh BT, Mamo B. Determinants of selected cardiovascular diseases among adult patients at cardiac clinic of Debre Berhan Referral Hospital, Ethiopia: unmatched case-control study. Cardiovasc Ther. 2020;2020. DOI:10.1155/2020/7036151

7. Lavie CJ, Ozemek C, Carbone S, Katzmarzyk PT, Blair SN. Sedentary behavior, exercise, and cardiovascular health. Circ Res. 2019;124(5):799-815. doi:10.1161/CIRCRESAHA.118.312669

8. De Backer G, Ambrosioni E, Borch-Johnsen K, et al. European guidelines on cardiovascular disease prevention in clinical practice $<$ SBT> Third Joint Task Force of European and other Societies on Cardiovascular Disease Prevention in Clinical Practice (constituted by representatives of eight societies and by invited experts). Atherosclerosis. 2004;173(2):379-389.

9. Omboni S, Caserini M. Effectiveness of pharmacist's intervention in the management of cardiovascular diseases. Open Heart. 2018;5(1): e000687. doi:10.1136/openhrt-2017-000687

10. George PP, Molina JA, Cheah J, Chan SC, Lim BP. The evolving role of the community pharmacist in chronic disease management-a literature review. Ann Acad Med Singapore. 2010;39(11):861-867.

11. Mossialos E, Courtin E, Naci H, et al. From "retailers" to health care providers: transforming the role of community pharmacists in chronic disease management. Health Policy. 2015;119(5):628-639. doi:10.10 16/j.healthpol.2015.02.007

12. Kii M. Projecting future populations of urban agglomerations around the world and through the 21st century. NPJ Urban Sustain. 2021;1 (1):10. doi:10.1038/s42949-020-00007-5

13. Belachew SA, Muluneh NY, Erku DA, Netere AK. A cross sectional study on beliefs and roles of community pharmacy professionals in preventing and managing metabolic syndrome in an Ethiopian setting. PLoS One. 2020;15(12):e0244211. doi:10.1371/journal.pone.0244211

14. Sia HP, Khan TM, Redzuan AM. Community pharmacists' perception and experience in providing lifestyle assistance to patients with cardiovascular disease. Int J Pharm Sci \& Res. 2020;11(9):4338-48. doi:10.13040/IJPSR.0975-8232.

15. Erku DA, Belachew SA, Mekuria AB, et al. The role of community pharmacists in patient counseling and health education: a survey of their knowledge and level of involvement in relation to type 2 diabetes mellitus. Integr Pharm Res Pract. 2017;6:137-143. doi:10. 2147/IPRP.S140777

16. Eades CE, Ferguson JS, O'Carroll RE. Public health in community pharmacy: a systematic review of pharmacist and consumer views. BMC Public Health. 2011;11(1):582. doi:10.1186/1471-2458-11-582 
17. Katoue MG, Awad AI, Kombian SB. Role of community pharmacists in the prevention and management of the metabolic syndrome in Kuwait. Int J Clin Pharm. 2013;35(1):57-64. doi:10.1007/s11096-012-9705-4

18. McKenney JM, Bradberry JC, Talbert RL, Cahill E, Brown WV. National survey of pharmacists about coronary heart disease, hypercholesterolemia, nonprescription statin therapy, and pharmacists' services. J Am Pharm Assoc. 2004;44(5):562-568. doi:10.1331/1544-3191.44.5.562.McKenney

19. Erku DA, Mersha AG. Involvement of community pharmacists in public health priorities: a multi-center descriptive survey in Ethiopia. PLoS One. 2017;12(7):e0180943. doi:10.1371/journal.pone.0180943

20. Hijazi MA, Shatila H, El-Lakany A, Al Rifai H, Aboul-Ela M, Naja F. Role of community pharmacists in weight management: results of a national study in Lebanon. BMC Health Serv Res. 2020;20(1):386. doi:10.1186/s12913-020-05258-7

21. Fonseca AA, Lima TM. Feasibility of cardiovascular risk screening in Portuguese community pharmacies. Pharm Pract. 2021;19 (2):2255. doi:10.18549/PharmPract.2021.2.2255

22. George J, McNamara K, Stewart K. The roles of community pharmacists in cardiovascular disease prevention and management. Australas Med J. 2011;4(5):266-272. doi:10.4066/AMJ.2011.698

23. Puspitasari HP, Aslani P, Krass I. Australian community pharmacists' awareness and practice in supporting secondary prevention of cardiovascular disease. Int J Clin Pharm. 2013;35(6):1218-1228. doi:10.1007/s11096-013-9854-0
24. Laliberté M-C, Perreault S, Damestoy N, Lalonde L. Ideal and actual involvement of community pharmacists in health promotion and prevention: a cross-sectional study in Quebec, Canada. BMC Public Health. 2012;12(1):1-11. doi:10.1186/1471-2458-12-192

25. El Hajj MS, Mahfoud ZR, Al Suwaidi J, Alkhiyami D, Alasmar AR. Role of pharmacist in cardiovascular disease-related health promotion and in hypertension and dyslipidemia management: a cross-sectional study in the S tate of Q atar. J Eval Clin Pract. 2016;22 (3):329-340. doi:10.1111/jep.12477

26. Rose G. Sick individuals and sick populations. Int $J$ Epidemiol. 1985;14(1):32-38. doi:10.1093/ije/14.1.32

27. Namara KPM, Dunbar JA, Philpot B, Marriott JL, Reddy P, Janus ED. Potential of pharmacists to help reduce the burden of poorly managed cardiovascular risk. Aust J Rural Health. 2012;20 (2):67-73. doi:10.1111/j.1440-1584.2012.01259.x

28. Horgan J, Blenkinsopp A, McManus R. Evaluation of a cardiovascular disease opportunistic risk assessment pilot ('Heart MOT'service) in community pharmacies. J Public Health (Bangkok). 2010;32(1):110-116. doi:10.1093/pubmed/fdp092

29. Almansour HA, Aloudah NM, Alhawassi TM, Chaar B, Krass I, Saini B. Cardiovascular disease risk prevention services by pharmacists in Saudi Arabia: what do policymakers and opinion leaders think? J Pharm Policy Pract. 2021;14(1):42. doi:10.1186/s40545-021-00319-6
Integrated Pharmacy Research and Practice

\section{Publish your work in this journal}

Integrated Pharmacy Research and Practice is an international, peerreviewed, open access, online journal, publishing original research, reports, reviews and commentaries on all areas of academic and professional pharmacy practice. This journal aims to represent the academic output of pharmacists and pharmacy practice with particular focus on integrated care. All papers are carefully peer reviewed

\section{Dovepress}

to ensure the highest standards as well as ensuring that we are informing and stimulating pharmaceutical professionals. The manuscript management system is completely online and includes a very quick and fair peer-review system, which is all easy to use. Visit http://www.dovepress.com/testimonials.php to read real quotes from published authors. 